\title{
Les Drassanes Reials de Barcelona, un edifici medieval i modern. Desenvolupament i resultats d'un projecte de recerca arqueològic i històric
}

\author{
Enric Garcia Domingo \\ InMa GonZÁLEZ SÁNCHEZ \\ Museu Marítim de Barcelona
}

\section{Resum}

L'estudi de les Drassanes Reials de Barcelona, seu del Museu Marítim de Barcelona, és una de les principals línies de recerca en les quals es treballa al Museu, tant des de la perspectiva de conèixer les vicissituds relatives a la seva construcció, com pel que fa al seu funcionament com a factoria, a l'impacte social i econòmic que va tenir al llarg de la seva dilatada història, i al seu encaix en la història marítima del país. En l'article s'explica com els diferents estudis realitzats i les excavacions arqueològiques ens han portat en els últims anys a replantejar-nos el discurs que es donava tradicionalment respecte a aquesta qüestió. I com el 2016 es va posar en marxa una recerca que se centra en l'estudi del període que es perfila com probablement el més intens de la historia de les Drassanes Reials: l'època moderna. El projecte, dissenyat fa dos anys, finalitzarà $\mathrm{amb}$ una publicació que recollirà els primers resultats, amb els quals el tema no quedarà esgotat, sinó que s'espera que sigui un punt de partida per a futurs estudis en els quals se segueixi aprofundint en el coneixement d'aquest extraordinari conjunt monumental.

Paraules clau: Drassanes Reials de Barcelona, Museu Marítim de Barcelona, arsenals, construcció naval, galeres. 
Las Atarazanas Reales de Barcelona, un edificio medieval y moderno. Desarrollo y resultados de un proyecto de investigación arqueológico e histórico

\title{
Resumen
}

El estudio de las Atarazanas Reales —Drassanes Reials_ de Barcelona, sede del Museu Marítim de Barcelona, es una de las principales líneas de investigación en las que se trabaja desde el Museo, desde diferentes perspectivas: las vicisitudes relativas a su construcción, su funcionamiento como factoría, el impacto social y económico que tuvo a lo largo de su dilatada historia y su encaje en la historia marítima del país. En el artículo se explica cómo los diferentes estudios realizados y las excavaciones arqueológicas nos han llevado en los últimos años al replanteamiento del discurso que se había dado tradicionalmente al respecto. Y cómo en 2016 se puso en marcha una investigación que incide en el estudio del período que se perfila como probablemente el más intenso de la historia de las Atarazanas Reales: la época moderna. El proyecto, diseñado a dos años, finalizará con una publicación que recogerá los primeros resultados, con los que no quedará agotado el tema, sino que se espera que sea un punto de partida para futuros trabajos en los que se siga profundizando en el conocimiento de este extraordinario conjunto monumental.

Palabras clave: Atarazanas Reales de Barcelona, Museu Marítim de Barcelona, arsenales, construcción naval, galeras.

\section{The Drassanes Reials of Barcelona, a medieval and early modern building. Development and results of an archaeological and historical research project}

\begin{abstract}
The study of the Drassanes Reials of Barcelona, that nowadays hosts the Museu Marítim de Barcelona, is one of the main lines of research in which the Museum works, at different levels: the chronology of its construction, the operational aspects of the shipyard as a factory, and the social and economic impact that it had throughout its long history. All this defines its place in the country's maritime history. The article explains how the different studies and archaeological excavations carried out in recent years have led us to review the traditional discourse on the subject. As a result, in 2016, an investigation was launched into the study of the period that is probably the most intense in the history of the Drassanes Reials, the early modern era. This two-year research
\end{abstract}


project will end in a publication containing the first results. This book will not exhaust the subject, but is expected to be a starting point for future studies that will continue to further our knowledge of this extraordinary monumental complex.

Keywords: Drassanes Reials de Barcelona, Museu Marítim de Barcelona, dockyard, shipbuilding, galleys.

\section{Justificació}

L'any 20I3, un cop finalitzades les obres de restauració de les Drassanes Reials de Barcelona, la direcció del Museu Marítim de Barcelona va confirmar una informació que des de feia alguns mesos es comentava de forma extraoficial: el conjunt arquitectònic, que es presentava en tota la seva esplendor, era un edifici bastit bàsicament al segle XVI i del seu passat medieval, doncs, en quedava molt poc. Es tractava d'unes drassanes modernes i això trencava el discurs oficial de «joia del gòtic medieval català» $\mathrm{i}$ «testimoni de l'esplendor de la Catalunya medieval», alhora que obria un nou paradigma que calia explicar i justificar. Curiosament, els mitjans de comunicació i una gran part del públic es preocupaven de saber si aquest canvi significava que les Drassanes Reials ja no eren gòtiques, però poca gent es plantejava perquè al segle Xvi s'havia reconstruït l'edifici pràcticament en la seva totalitat. En general, es feia palesa una ignorància total del que significava posar el focus en un període poc i mal conegut de la història de la ciutat i del Principat, i semblava preocupar més la minva de valor d'un passat medieval que no pas conèixer el que amagava aquest «nou passat» modern. 


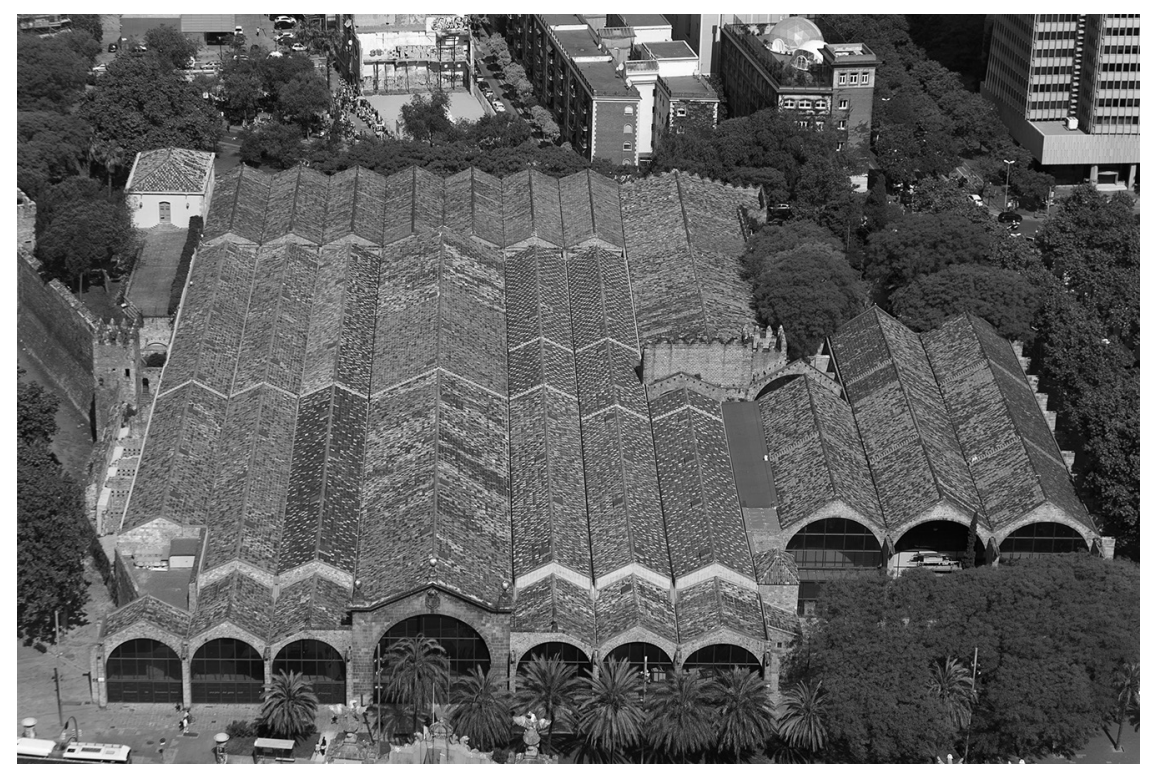

Figura I. Vista aèria de l'edifici de les Drassanes Reials de Barcelona en l'actualitat (2013) (MMB; foto: Diego Yriarte).

Aquell mateix any 2013 el Museu va publicar un llibre resum de la història del conjunt, a la vista del canvi de versió oficial, en el qual es justificava aquest gir de guió $\mathrm{i}$ es transmetia a la ciutadania que no es tractava en cap cas de perdre valor, sinó d'obrir una nova porta que comportaria sorpreses i revaloraria encara més aquest arsenal de galeres. ${ }^{\mathrm{I}}$ No gaire més tard, es va posar en marxa un projecte de recerca específic sobre les Drassanes modernes per tal de donar resposta a la necessitat de saber més sobre aquest nou paradigma. Aquest article dona algunes de les claus necessàries per comprendre el com i el perquè d'aquest projecte. Cal, abans, fer una mínima introducció per tal de situar l'escenari en el seu context.

I. Silvia Dahl, Enric García i Olga López, Les Drassanes Reials de Barcelona, Museu Marítim de Barcelona, Barcelona, 20I3. 
El Museu Marítim de Barcelona té la seva seu a l'edifici de les Drassanes Reials de Barcelona; o, dit d'una altra manera, les Drassanes Reials de Barcelona alberguen les colleccions del Museu Marítim, amb la qual cosa es converteix l'edifici en una de les peces fonamentals del Museu, i del seu discurs expositiu, per explicar la història marítima de la ciutat. Poques vegades contingut i continent estan vinculats tan estretament. Aquesta confluència del Museu i l'edifici va ser possible gràcies que l'exèrcit espanyol, propietari de l'edifici, i l'Ajuntament de Barcelona van arribar a un acord de permuta que va permetre traslladar el parc d'artilleria que hi havia a les Drassanes, a uns nous equipaments a Sant Andreu. El trasllat dels efectius militars es va fer a principis del 1935 i aquell mateix any el consistori va aprovar convertir les Drassanes en un equipament cultural. El procés es va accelerar amb l'esclat de la Guerra Civil i el 20 d'octubre de 1936 el conseller en cap de la Generalitat, Josep Tarradellas, va signar un decret on s'explicitava clarament:

La necessitat d'installlar el Museu Marítim de Catalunya en un lloc avinent [....], aconsella destinar per a Museu Marítim la part antiga de les Drassanes, indret nobilíssim per l'arquitectura i la tradició marítima de Catalunya que evoca. L'Ajuntament de Barcelona havia decidit destinar a finalitats culturals l'edifici de les antigues Drassanes, bon punt fossin aptes per a alguna installlació. Ha arribat ara el moment de fer-hi la installlació definitiva del Museu Marítim de Catalunya. ${ }^{2}$

Així doncs, des del 1936 els responsables del Museu han tingut cura del conjunt d'edificacions de les Drassanes Reials, que gaudeix de la màxima protecció legal: va ser inclòs en el Registre de Patrimoni Històric, Artístic i Científic de Catalunya l'any 1937 i va ser declarat Monument Històric Artístic d'Interès Nacional mitjançant el Decret del Consell de Ministres de 5 de març de 1976. L'any 1985 es va redactar el Pla Director de Reforma i Restauració de les Drassanes Reials, que

2. Sobre aquest període, vegeu Enric García Domingo, Història del Museu Maritim de Barcelona 1929/1939, Museu Marítim de Barcelona / Angle, Barcelona, 200I. 
tenia com un dels seus objectius la restauració integral del conjunt monumental de les Drassanes, la muralla i el baluard. ${ }^{3}$

Per posar fi a la confusió institucional existent (edifici municipal des del 1935 i museu de la Diputació de Barcelona des del 1939), l’any I993 es va crear el Consorci de les Drassanes Reials i Museu Marítim de Barcelona, que gestiona des de llavors el conjunt i el seu contingut. El Consorci està format per l'Ajuntament de Barcelona, la Diputació de Barcelona i l'Autoritat Portuària de Barcelona. Segons els seus estatuts, el Consorci de les Drassanes Reials i Museu Marítim de Barcelona és un ens consorciat públic de caràcter local que té per objecte, entre altres coses, la conservació i la rehabilitació del conjunt patrimonial immoble on s'allotgen les Drassanes Reials i el Museu Marítim de Barcelona.

Sembla clar que l'estudi de l'edifici al llarg de la seva història és una de les missions ineludibles que ha d'afrontar la institució. Però en realitat ha estat molt recentment que el Museu Marítim de Barcelona ha posat en marxa un projecte de recerca sòlid i coherent. Des de l'any 2006 l'estudi de l'edifici de la institució i, de retruc, dels arsenals històrics de la Mediterrània, és una de les principals línies d'investigació de l'Observatori Permanent d'Història i Cultura Marítima de la Mediterrània. ${ }^{4}$

Aquest conjunt arquitectònic, començat a construir al segle XIII, té una vida molt llarga com a arsenal de marina i com a caserna, com a foneria de canons i com a museu, com a presó i com a drassana. Més

3. Robert Terradas Muntañola i Esteve Terradas Muntañola, "El Pla director de les Drassanes de Barcelona i els projectes», Drassana, 5 (1996), pp. I3-I8.

4. La creació de l'Observatori Permanent d'Història i Cultura Marítima de la Mediterrània va ser aprovada pel Consell General del Consorci de les Drassanes Reials i Museu Marítim de Barcelona el I3 de desembre de 2006, amb la finalitat de fomentar les activitats de recerca de caire interdisciplinari per conèixer més i millor el nostre passat vinculat al mar i les manifestacions que ahir i avui ha generat aquesta vinculació, per donar impuls i gestionar els programes de recerca a través de diverses línies de treball, fer divulgació i comunicació pública de tot el coneixement generat per aquests programes d'investigació, i fomentar la recerca mitjançant la captació de fonts de finançament. A partir de la seva creació, el Museu va iniciar contactes amb altres institucions que se sumessin a aquesta iniciativa; per exemple, la Universitat de Barcelona es va incorporar al projecte a través de la signatura d'un conveni d'adhesió l'any 2007. 
de set-cents anys plens d'esdeveniments. En aquest article hem resumit les iniciatives del Museu Marítim de Barcelona pel que fa al foment del coneixement, hem posat el focus en la recerca que té per objecte l'estudi de les Drassanes Reials d'època moderna i hem seleccionat les actuacions que ens illustren el problema del gran arsenal de la corona hispànica en els segles XVI-XVIII.

\section{El projecte de recerca Drassanes Reials de Barcelona}

2.I. Una manera diferent d'afrontar la recerca: la dualitat edifici/institució

Cal entendre les Drassanes Reials (ens hi podem referir en singular o en plural, tot i que és més comú utilitzar el plural per tal de potenciar la idea de conjunt, i no la d'un edifici únic) com una institució i com una installació relacionada amb l'activitat naval de la Corona, de Barcelona i de la Generalitat entre els segles XIII i XvIII. Per tant, estem davant d'un fenomen que s'expressa en una dimensió institucional, econòmica, espacial i social. Per tant, per aconseguir una mínima comprensió i interpretació de la seva història cal integrar dades aportades per diverses fonts i utilitzar els registres documentals aportats per les diferents disciplines que configuren la història (arqueologia, paleografia, història de l'art).

Durant dècades, els estudis sobre les Drassanes Reials de Barcelona es van focalitzar en el període medieval, entre el segle XIII fundacional (en circumstàncies poc definides i actualment una mica més clares) i el segle Xv de decadència institucional de la Corona d'Aragó. En aquestes aproximacions l'objecte d'estudi era sobretot la història de l'edifici i les seves fases constructives. Deixant de banda l'estudi clàssic i pioner de Francesc Carreras Candi, 5 fins l'any 2000 hem de destacar dues grans

5. Francesc Carreras i Candi, Les dreçanes barcelonines: Sos inventaris y restauració, Táber, Barcelona, 1928. 
aportacions, ben diferents: en primer lloc, una benintencionada síntesi sobre les Drassanes publicada l'any 1943 per Francesc Condeminas, director del Museu, amb el títol Las Reales Atarazanas de Barcelona, adreçada sobretot a realçar el valor del conjunt als ulls de la ciutadania (i també de les autoritats); en segon lloc, un projecte de recerca dirigit l’any 1988 pel Dr. Antoni Riera Melis, de la Universitat de Barcelona, i titulat «Las Reales Atarazanas de Barcelona. Estudio de su construcción y funcionamiento». ${ }^{6}$

Vers l'any 2000, sota l'impuls del director del Museu, Roger Marcet, els tècnics del Museu van prendre la determinació de trencar aquesta inèrcia de dècades i adoptar una política més activa. Es tractava de començar a pensar en accions concretes destinades a conèixer les Drassanes Reials des de tots els punts de vista. Totes aquestes iniciatives s'agrupen sota el nom de projecte Drassanes Reials de Barcelona.

El 2003, amb el projecte Drassanes en procés de gestació, es presenta un dossier dedicat a les Drassanes i el seu món al número in de la revista Drassana, del Museu Marítim de Barcelona, amb els articles següents: «Les Drassanes Reials de Barcelona a la baixa edat mitjana» (Albert Estrada), «La Drassana i la gestió de la façana marítima de Barcelona» (Albert Cubeles i Ferran Puig), «Equipament sanitari de l'armada de la ciutat de Barcelona contra el cors capitanejada per Jaume Bertran (I454)» (Víctor Mata i Xavier Sorní), «Noves aportacions de l'arqueologia a la història de les Drassanes Reials de Barcelona» (Daria Calpena) i «De drassanes i drassaners: Eloi Navel (†I457), un drassaner lletraferit»(J. Antoni Iglesias). D'entre tot aquest material es pot destacar l'aportació de Cubeles i Puig, pel que representà com a capdavantera del replantejament de la visió de l'edifici que teníem fins llavors.

6. Aquest treball incloïa buidats documentals de gran interès: tasts a l'Arxiu de Simancas (J. Torner Planell, I99I), transcripció de les deliberacions del General de Catalunya (A. Guallar, 199I), estudi de les deliberacions del General de Catalunya del trienni I62I-I623 referents a l'esquadra del Principat (M. Hispano, I993), glossari dels inventaris de les Drassanes de Barcelona del segle xv i altres transcripcions (1993-1994), i una aproximació a la investigació sobre protocols de l'Arxiu Històric de Protocols de Barcelona (E. J. Rodríguez Martínez i F. X. Teruelo de Luis, I995). 
La direcció del Museu va impulsar a partir de l'any 2006 una iniciativa original: dissenyar un pla de recerca tan coherent com fos possible per tal d'optimitzar esforços i avançar en el coneixement del conjunt i de la institució. I el punt de partida va ser la creació del Laboratori Drassanes Reials de Barcelona, un espai de reflexió i debat que aplegava algunes persones que es movien en la nostra òrbita i volien fer les seves aportacions. Entre l'octubre del 2006 i el març del 2007 es van celebrar diferents reunions en les quals van participar Ferran Puig, Albert Cubeles, Esteve i Robert Terrades, Francisco Segovia, Albert Estrada, Frederic-Pau Verrié i, per part del Museu, Roger Marcet, Elvira Mata, Olga López i Enric Garcia. Les reunions de treball s'articulaven al voltant d'un tema, amb una presentació prèvia i una discussió posterior. Per exemple, els antecedents i les Drassanes Reials amb funció naval, les diferents etapes constructives de l'edifici i la seva evolució arquitectònica, les Drassanes i la ciutat de Barcelona, les Drassanes com a arsenal i les Drassanes com a caserna. Es van tornar a celebrar sessions el 27 d'abril i el 30 de novembre de 2010 i una altra el i4 de juny de 20II. Com que l'any 2010 es va iniciar la darrera fase de restauració de l'edifici, amb la restauració integral del conjunt, aquesta oportunitat de treballar sobre el subsòl de l'edifici va coincidir, doncs, amb el replantejament de la seva història i va tenir sobretot una conseqüència clara consistent en la confirmació del que fins llavors era una sospita fonamentada: que la major part del conjunt existent s'havia bastit en el segle Xvi i que només una part de l'edifici medieval havia estat preservada.

En les conclusions d'un encàrrec fet pel Museu a l'Albert Cubeles entre el 2007 i el 20107 s'avançava que durant molt temps la historiografia havia considerat les Drassanes Reials com una expressió material molt contundent de la potència assolida per la marina catalana medieval, però aquesta apreciació entrava en crisi perquè marginava l'època moderna. Per exemple, quan es treballava amb la planimetria històrica conservada a l'Archivo General de Simancas, ara sabem que es plante-

7. Es tracta d'un encàrrec de la Fundació Privada Museu Marítim de Barcelona, titulat «Les relacions històriques entre la Drassana Reial i la ciutat de Barcelona» (inèdit). 
java un problema de focus. S'interpretava sempre com una foto fixa de cada moment, amb unes Drassanes medievals mantingudes i ampliades a partir del segle XVI com a creixement natural del conjunt medieval i mai vistes com una obra nova i original en ella mateixa. S'encaixava en el discurs oficial i en cap moment es plantejava que les Drassanes modernes s'haguessin d'estudiar com un edifici amb entitat pròpia. Per altra banda, s'apuntava quins podien ser els eixos en què s'hauria de treballar per tal d'establir un marc general sobre les Drassanes Reials.

Cal ara tornar una mica enrere. L'any 2004 es posa la primera pedra del nou estil amb la publicació del llibre d'Albert Estrada-Rius. Era el resultat d'una nova metodologia. El Museu encarregava un estudi, feia les preguntes i buscava un investigador que pogués trobar-hi respostes coherents. Calia fer balanç del que s'havia fet fins a aquell moment i, sobretot, sintetitzar els nostres coneixements sobre el gran moment de les Drassanes medievals. Aquest estudi, que portà a terme el Dr. Albert Estrada, va dibuixar l'estat de la qüestió agrupant totes les investigacions que s'havien dut a terme fins aleshores. Va ser publicat amb el títol $\mathrm{La}$ Drassana Reial de Barcelona a l'Edat Mitjana. Organització institucional i construcció naval a la Corona d'Aragó (publicat a la collecció «Estudis del MMB», número 4, 2004). En aquest treball, a més d'analitzar tots els estudis parcials sobre l'edifici de les Drassanes Reials que s'havien fet fins llavors, es feia un canvi radical i s'analitzaven també els usos del conjunt arquitectònic.

En una segona fase complementària, el Dr. Estrada va cercar respostes als interrogants que plantejava l'edifici, conegut tradicionalment com l'edifici de Pere IV. La recerca estudia el que era en realitat la Botiga Nova del General, un magatzem de la Generalitat en el conjunt de la Drassana Reial. Es tracta d'una estructura arquitectònica de la qual es desconeixia gairebé tot, i molt especialment el seu sentit i la seva funció. El treball va ser publicat l'any 2008 en la colllecció «Estudis del MMB» amb el títol La Generalitat de Catalunya a la Drassana Reial de Barcelona en temps d'Alfons el Magnànim. En aquest context tan particular es va plantejar la resolució d'algunes de les incògnites que envolten obres tan significatives com la desapareguda Casa del General a 
prop de la Llotja de Mar de Barcelona o la Casa del General a Perpinyà. Sobre l'edifici de la Drassana Reial de Barcelona, s'aporten dades sobre la construcció a partir del I443 i per part de la mateixa Diputació, d'aquesta ja esmentada Botiga Nova del General.

En la mateixa línia d'aquest encàrrec, l'any 2007 se'n va formalitzar un altre per realitzar un nou estudi que feia un salt en el temps i ens portava a conèixer les Drassanes entre els segles XVIII i XX. Es va encarregar al coronel d'Infanteria Francisco Segovia, expert en història militar, el qual va traçar un retrat de les Drassanes Reials des del punt de vista del seu ús no naval. Tot i que aquests usos van començar ja en època medieval, l'estudi bàsicament comprèn els segles XVIII i XIX. El treball va ser publicat amb el títol Las Reials Drassanes de Barcelona, entre I700 y 1936. Astillero, cuartel, parque y maestranza de artillería, Real Fundición de bronce y fuerte, en la col.lecció «Estudis del MMB», número I3, l'any 2008. Francisco Segovia analitza aquesta etapa i posa al descobert que a la segona meitat del segle Xvin aquest recinte es va arribar a convertir en un complex militar industrial i en foneria de bronze i tornejament de canons, a més de caserna, parc i mestrança d'artilleria, tot aquest conjunt aillat i amb fortificació pròpia. També narra la seva posterior i progressiva desmilitarització. Aquest estudi deixava, com era habitual, una finestra temporal sense estudiar: els segles XVI i XVII.

Les darreres aportacions van quedar emmarcades en els treballs de restauració de l'edifici i es van recollir en un dossier dedicat a les Drassanes i publicat al número I9 de la revista Drassana (2012) amb els articles següents: "Les tecnologies de la informació geogràfica (TIC) i la reconstrucció històrica del conjunt de les Drassanes Reials de Barcelona. Aproximació i perspectives», de Víctor M. Cabral Rodrígues; "Evolució de la imatge de les Drassanes de Barcelona», de Robert Terradas; «La documentació integral del patrimoni construït aplicada a l'estudi històric i estructural de les Drassanes Reials de Barcelona. El Portal de la Pau, la casa de Manteniment i la Casa del Governador», d'Eloi Castells, Helena Moran i Núria Nolasco; «Museo Marítimo de Drassanes: levantamiento con escáner láser terrestre, planimetría y modelo $3 \mathrm{D}$ ", d'Alejandro Marambio, Juan Corso i Pilar García-Almirall, i «Noves 
dades, noves perspectives i nous objectius en l'estudi històric de la Drassana Reial de Barcelona», d'Albert Cubeles Bonet.

No tots els nostres coneixements provenen de la recerca històrica tradicional. També les intervencions arquitectòniques i arqueològiques anteriors al 2010 van ajudar a avançar una mica en aquest sentit. L'any 1936, tan bon punt la Generalitat de Catalunya va fer-se càrrec de l'edifici, van començar els primers treballs de restauració del conjunt, especialment en les àrees que havien de ser l'exposició permanent del $\mathrm{Mu}$ seu. Però, llevat de la troballa casual d'uns enterraments no identificats, no es va fer res digne de consideració. Després de la Guerra Civil l'edifici va quedar molt malmès i a partir dels anys quaranta i fins als setanta es van dur a terme diferents actuacions de recuperació i restauració de l'edifici, de les quals cal destacar les realitzades per l'arquitecte municipal, Adolf Florensa, que amb les seves actuacions sobre l'edifici va definir els criteris futurs i va deixar les Drassanes tal com les coneixem actualment. ${ }^{8}$

Com ja s'ha avançat, entre els anys 1985 i 1986 es va redactar i aprovar el Pla d'Actuació i Ordenació de les Drassanes Reials de Barcelona, que establia les reformes $\mathrm{i}$ restauracions necessàries tant per utilitzar d'una manera coherent tot l'espai edificat com per millorar la relació del conjunt de les Drassanes amb la ciutat. El Pla, redactat pels arquitectes Robert Terradas i Esteve Terradas, va ser actualitzat el 1999, executat en diferents moments i fases, i finalitzat formalment el 20I3. Durant aquest llarg període es van realitzar diferents obres, algunes acompanyades d'excavacions d'urgència. ${ }^{9}$ És a dir, entre el 1936 i el 2010 el conjunt

8. Sobre aquest personatge, vegeu Oriol Bohigas i Guardiola, Conxita Comamala, Jordi Oliveras i Manuel Ribas Piera, Adolf Florensa i Ferrer (I889-1968), Ajuntament de Barcelona, Barcelona, 2002, collecció Gent de la Casa Gran.

9. Intervenció en la restauració i l'adequació de la sala Marqués de Comillas (1987-1989); intervenció en les sis crugies últimes de l'edifici de Pere IV i creació de la nova entrada pels Jardins del Rei (1990); intervenció en la restauració i l'adequació de la nau de la Generalitat (1994-1995); recuperació per al Museu del porxo del passeig de Josep Carner com a continuació de les grans naus, finalització de la restauració i habilitació de l'edifici de Pere IV i adequació de les naus del segle XviI, dites de la Generalitat (2002-2003). 


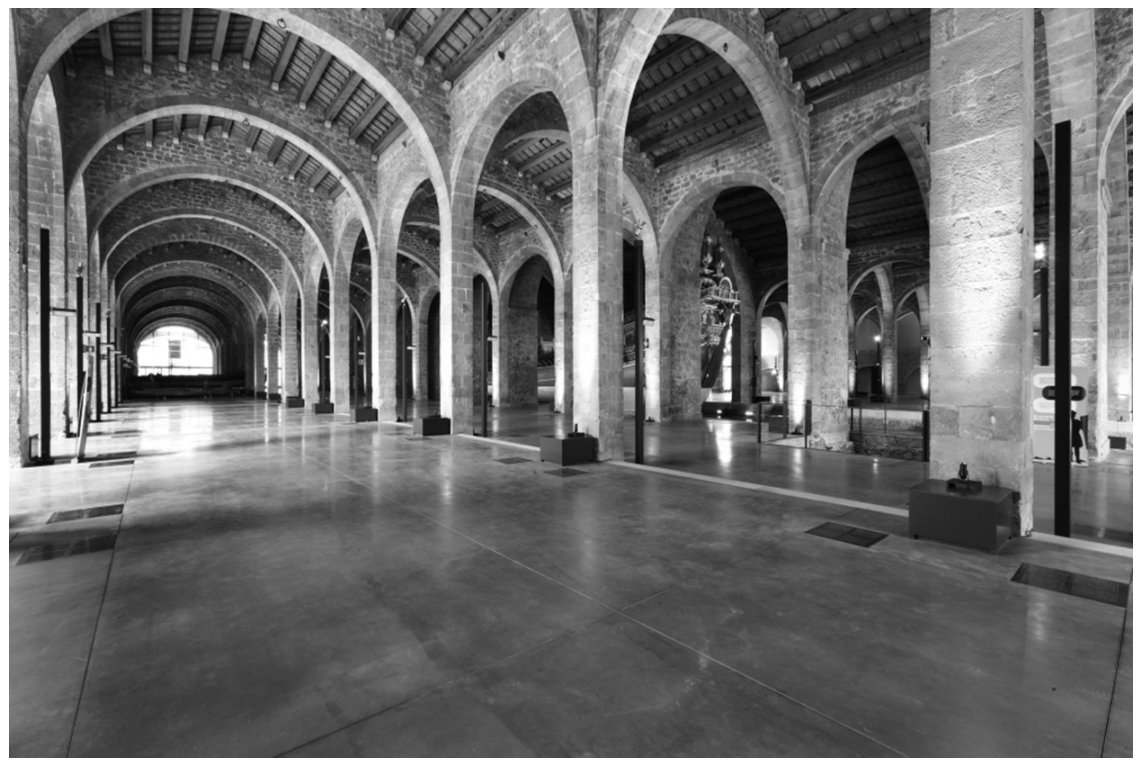

Figura 2. Vista de l'interior de les naus de les Drassanes Reials de Barcelona una vegada finalitzades les obres de restauració al 2013 (MMB; foto: José Biel).

havia estat objecte d'intervencions arquitectòniques i d'altres excavacions puntuals, gens sistemàtiques i en general mal documentades. ${ }^{10}$

El 2009 es va posar en marxa la realització d'un model en $3 \mathrm{D}$ amb escaneig làser terrestre (TLS), un mètode ràpid, precís i eficient de recollida de dades tridimensionals sobre els edificis. Permet la generació

IO. Alguns altres estudis realitzats van resultar poc transcendents, però demostren l'interès del Museu per identificar qualsevol mitjà que tingués a l'abast (i sobretot assumible econòmicament) per augmentar els coneixements sobre el conjunt. És just esmentar-los: estudis geotècnics fets pel Departament de Geoquímica, Petrologia i Prospecció Geològica de la Facultat de Geologia (UB), dirigit pel professor Albert Permanyer, sobre la patologia de la maçoneria de l'edifici (I989); estudis amb georadar fets per l'empresa Radarprospec SL per tal d'enregistrar perfils subterranis (I990I99I); estudi geotècnic de tres cales de mostra fet per l'empresa Batlle \& Mascareńas Geoprojectes SL (2000); estudis geotècnics fets per un equip de la Facultat de Geologia (UB), concretament del Departament de Geoquímica, Petrologia i Prospecció Geològica, dirigit pel professor Alberto Casas (2008). 
d'un model tridimensional a partir del qual es poden obtenir plànols exactes o models virtuals per a aplicacions de realitat augmentada. El TLS va permetre, per primer cop, obtenir una planimetria completa i exacta de l'edifici. ${ }^{\text {II }}$ Malauradament, aquest estudi va fer-se sense saber que un any més tard podríem iniciar les obres definitives de restauració, de manera que el resultat va ser incomplet i precipitat.

Igualment importants van ser els estudis de georeferenciació fets entre els anys 2009 i 20I0. Es tractava de georeferenciar el conjunt de les Drassanes Reials de Barcelona i fer una selecció de la planimetria antiga que s'ha conservat. En la primera fase es van implementar les bases de referència, es van establir les coordenades, es van realitzar els càlculs, etc., tasca que va fer l'empresa Geo Informáticos. En la segona fase es van georeferenciar dades històriques i arqueològiques a partir de la planta actual i d'una selecció de vuit planimetries antigues, treball que permet situar amb coordenades reals la planimetria del conjunt $\mathrm{i}$ inserir-hi, per exemple, totes les evidències arqueològiques observades a partir de les excavacions realitzades en els darrers cinquanta anys. Els treballs van ser realitzats per l'arqueòleg Víctor M. Cabral, qui va muntar amb el programari Miramón una selecció de planimetria històrica més la planta actual més la planimetria de les intervencions arqueològiques documentades. Aquest treball va ser continuat per Marta del Mastro.

Finalment, cal esmentar una altra metodologia aplicada a les Drassanes Reials: els estudis arqueoarquitectònics, que permeten saber què ha portat una edificació històrica a tenir la fesomia que ens mostra avui i quins són els materials constructius i els elements arquitectònics que l'han caracteritzat al llarg de la seva història. L'empresa Veclus va realitzar tres projectes concrets, vinculats a les obres de restauració. ${ }^{12}$

II. Els treballs van ser realitzats per l'equip del Laboratori de Modelització Virtual de la Universitat Politècnica de Catalunya, dirigit per la Dra. Pilar García-Almirall.

I2. Podeu trobar una relació més detallada de totes les aportacions a Olga LópeZ i Enric García, «Les Drassanes Reials de Barcelona, redescobertes», L’Avenç, 38I (juliol-agost 2012), pp. 42-53. 


\section{Les Drassanes Reials en època moderna}

\section{I. El replantejament}

Cal deixar constància que entre els anys 2006 i 20I3, abans i durant les obres, es van plantejar moltes preguntes $i$ es van fer estudis molt variats per anar sumant coneixement, de manera que les conclusions posades sobre la taula a partir del 20I3, pel que fa a la realitat de les Drassanes Reials d'època moderna, no són fruit només de l'arqueologia, sinó que aquesta va permetre confirmar i documentar hipòtesis ja avançades. Però el cert és que va ser a partir del 2010 que l'estudi de les Drassanes Reials va progressar exponencialment, i en part la clau ha estat un replantejament de la metodologia de treball i també del discurs oficial sobre la història de l'edifici de les Drassanes Reials.

El punt d'inflexió és el moment de les obres de restauració del conjunt, que comencen l'any 2010 i permeten una excavació arqueològica extensiva, impossible anteriorment. Abans, amb el Museu obert al públic, era impossible plantejar-se un tractament arqueològic més enllà de les intervencions d'urgència. És a partir d'aquesta darrera intervenció arqueològica que es fa un replantejament de la història oficial del conjunt, iniciada per Carreras Candi l'any 1928 i mantinguda al llarg dels anys amb poques variacions. Això és, unes drassanes medievals, "gòtiques», que van tenir la seva gran època entre els segles XIII i XV i que, acabat aquest gran moment, van perdurar en el temps amb diferents ampliacions fins que l'any 1745 van deixar de ser un arsenal de galeres i van passar a tenir usos militars fins al 1936. En aquest discurs ja s'encaixaven fets com la preparació de l'expedició de Carles I a Tunis el I535, o la campanya que va finalitzar amb la batalla de Lepant l'any I57I, però es plantejaven com uns fets puntuals, com a «jornades» situades en un moment de pura supervivència de les Drassanes Reials un cop oblidat el seu moment de glòria medieval.

Malgrat l'oblit general o la infravaloració de l'època moderna, cal dir que s'havien llegit tres tesis doctorals que, de forma indirecta, estaven cridant l'atenció sobre el valor del conjunt en aquest període, tot i 
que sense apartar-se de la història oficial. La primera va ser la tesi doctoral de Robert Terradas, un dels autors del Pla d'Actuació i Ordenació de les Drassanes Reials de Barcelona del i986. Titulada «Les Drassanes de Barcelona: la geometria, la traça i l'estructura com a garants de la identitat de l'edifici» i dirigida per la Dra. Teresa Rovira i Llobera, plantejava una teoria modular de l'edifici i apuntava alguna de les coses que les excavacions demostrarien, però sempre des de la mirada de l'arquitecte. ${ }^{13}$ L'altra tesis era la de Damià Martínez, "Giovan Battista Calvi: ingeniero de las fortificaciones de Carlos V y Felipe II (I552-I565)», dirigida pel professor Marià Carbonell Buades, que incorporava un capítol sobre el baluard del Rei, construït al segle Xvi. Finalment, cal esmentar la tesi de Jordi Gilabert Tomás, «La defensa contra el cors musulmà a la Catalunya dels Àustria», dirigida pel professor Carlos Martínez-Shaw i la qual incorporava un capítol dedicat a l'esquadra de galeres de la Generalitat de Catalunya (I599-I623).

Dit això, aquests estudis no van provocar cap replantejament de la història oficial, tot i que existien dubtes importants. Per exemple, en el moment d'interpretar els documents iconogràfics més antics on apareixen les drassanes, és a dir, les vistes de Barcelona fetes per Anton van der Wyngaerde l'any I563 (National Bibliotheck de Viena) o el dibuix que apareix a Civitates Orbis Terrarum, que mostra una vista de la ciutat pels volts del $1535,{ }^{\mathrm{I}}$ es plantejaven dubtes sobre com calia interpretar els documents respecte a l'edifici que es conserva. La tendència general era acceptar que els dibuixos mostraven unes Drassanes Reials idealitzades, que no es corresponien amb el que nosaltres podíem veure en directe. En cas contrari, es tractaria d'un edifici diferent del que conservem actualment, idea que va ser rebutjada a priori. Només el desenvolupament de

13. Robert Terradas Muntañola, Les Drassanes de Barcelona: la geometria, la traça i l'estructura com a garants de la identitat de l'edifici, Universitat Ramon Llull, Barcelona, 2008.

I4. R. L. Kagan, dir., Ciudades del Siglo de Oro. Las vistas españolas de Anton van der Wyngaerde, El Viso, Madrid, 1986; Georg Braun i Frans Hogenberg, Civitates Orbis Terrarum (1572), ed. de José Luis Casado Soto i Agustín Hernando, CM, Salamanca, 20I5. 
les excavacions arqueològiques $\mathrm{i}$ la discussió de les hipòtesis dels arqueòlegs sobre el terreny van permetre encaixar ambdues realitats amb una explicació coherent: la major part de l'edifici que conservem actualment no es correspon amb la drassana medieval original (de la qual es conserva una part relativament petita), sinó que es tracta d'un conjunt construït al segle XVI, en una cronologia encara per especificar. ${ }^{15}$

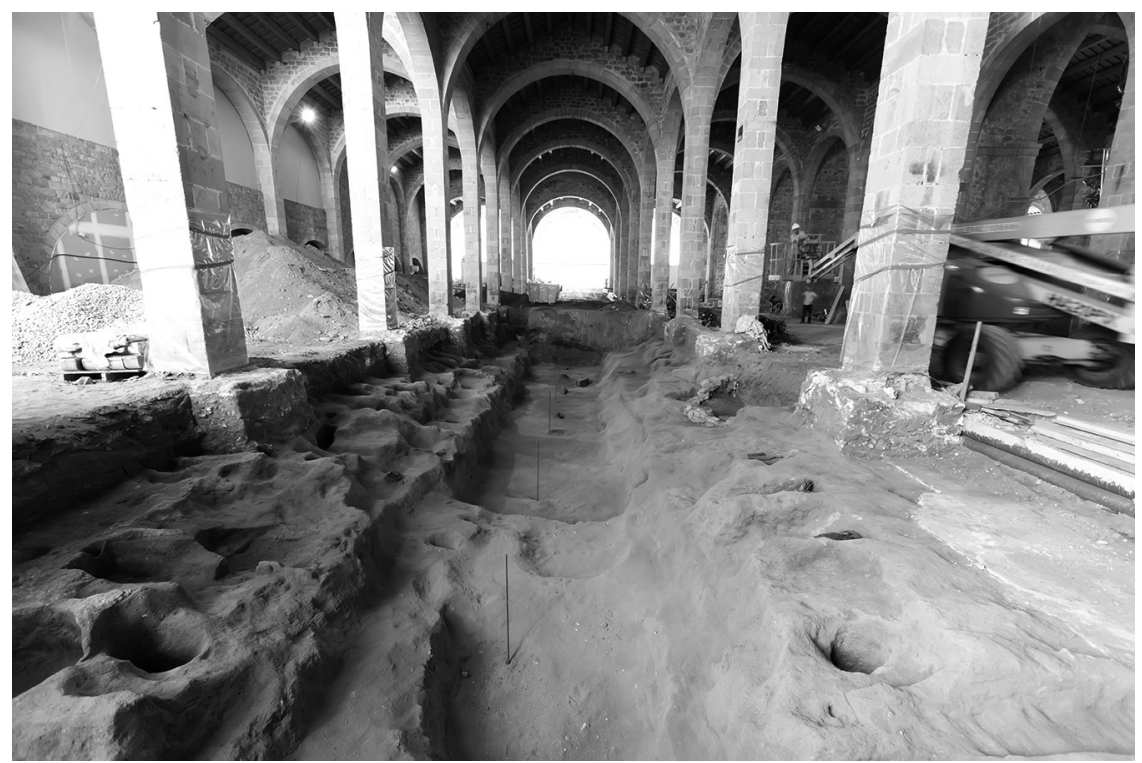

Figura 3. Vista de la grada de construcció de galeres que va sortir durant

l'excavació arqueològica, una estructura amb un pendent de $3^{\circ}$ cap a mar, una amplada de 8 metres, una profunditat màxima de $1,70 \mathrm{~m}$ i una llargada d'uns $40 \mathrm{~m}$.

Tot al voltant es poden apreciar els forats dels puntals per a la construcció. La seqüencia estratigràfica data l'ús de la grada al segle XvII (MMB; foto: José Biel).

La conclusió, un cop acabades les obres el 20I3, era inapel.lable: calia reescriure la història oficial de l'edifici i de la institució. Els esfor-

15. Albert Cubeles i Bonet, Ińaqui Moreno i Esteve Nadal, «Noves descobertes arqueològiques a la Drassana reial de Barcelona», Revista de Catalunya, 278 (2012), pp. II7-I39. 
ços de la institució havien de concentrar-se, en els propers anys, en la recerca sobre els segles XVI, XVII i XVIII, un territori per descobrir.

\subsection{El projecte de recerca: objectius i definició}

Per tal de completar les dades aportades per l'arqueologia i tots els estudis previs realitzats al llarg dels últims anys, des del Museu es va veure la necessitat d'aprofundir en els pròxims anys en l'estudi del que es perfila com probablement el període més intens de la història de les Drassanes Reials com a equipament preindustrial. Davant d'aquest escenari, calia impulsar un projecte de recerca concret que focalitzés la mirada en els segles XVI i XVII, amb una extensió cap a la primera meitat del Xviı fins al final de les Drassanes Reials com a arsenal de marina el I745 i la dissolució del cos de galeres l'any I748.

El Museu Marítim de Barcelona es va posar a treballar per dissenyar un projecte en aquesta línia: en primer lloc, marcant uns objectius ambiciosos però assolibles; en segon lloc, mirant d'aconseguir una partida pressupostària per poder iniciar els treballs; i en tercer lloc, dotant el projecte dels recursos humans necessaris per poder-lo desenvolupar dins d'un calendari a mitjà termini.

L'objectiu inicial que es va marcar el projecte era esbrinar i indagar les causes i motivacions que van fer possible que al segle Xvı es fes una gran inversió econòmica i d'esforços en la construcció de l'edifici de les Drassanes que veiem en l'actualitat. Calia, doncs, en primer lloc, dibuixar el marc institucional en el moment de la creació de la Monarquia Hispànica i veure com els canvis de poder van afectar l'administració de les Drassanes i, sobretot, el seu valor estratègic. Era necessari fer un retrat que emmarqués la reconstrucció arquitectònica de l'edifici després dels problemes estructurals de mitjan i finals del segle Xv i que pogués explicar i documentar en quin moment es va decidir fer les obres de reconstrucció i quines eren les ampliacions i reformes previstes i quines les efectivament realitzades, així com la justificació de la inversió en el context històric general.

Una altra pregunta que s'intentava respondre era com funcionava la factoria. Per fer-ho, hom l'havia de situar correctament en el context de 
la xarxa de drassanes de la Corona, per tal d'explicar de manera detallada el funcionament de la factoria naval tant des del punt de vista de la seva estructura administrativa com des del punt de vista de la construcció naval, dels oficis, les categories, les condicions laborals, la logística de funcionament, el volum de treball segons les diferents èpoques, les xarxes de subministrament, etc. Finalment, fins allà on fos possible, calia valorar l'impacte econòmic i social a la ciutat i al territori.

Amb aquestes premisses de partida es va redactar un document per tal de cercar finançament. El projecte es va dotar amb $30.000 €$ i va assumir el finançament la Fundació Suport Museu Marítim i Drassanes Reials de Barcelona. ${ }^{16}$ Es va dissenyar un projecte bianual dividit en dues parts, amb una divisió cronològica justificable per facilitar l'acostament i fer-lo més abastable. Aquestes dues parts les treballarien simultàniament dos investigadors diferents, de manera que hi pogués haver un cert intercanvi d'informació i la màxima coordinació possible en la cerca de la documentació als diferents arxius, a fi que es poguessin ajudar i donar suport, tot i que cada investigador se centrés en el seu període. Les dues parts es van dividir: la primera es va centrar en el segle Xvi, en els regnats de Carles I Felip II, i la segona es va centrar en el segle XvII, en els regnats de Felip III, Felip IV i Carles II, així com en l'impacte del canvi de dinastia a principis del xvIII, i va arribar fins al moment del cessament de l'activitat com a arsenal el I745.

Es va establir un calendari general del projecte de dos anys: del setembre del 2016 al setembre del 20I8. El desenvolupament del projecte havia d'anar passant per tres moments, que cada un dels investigadors podia distribuir com li resultés més convenient al llarg de la investiga-

I6. La Fundació Museu Marítim i Drassanes Reials de Barcelona es va crear el 9 de febrer de l'any 2006. La seva finalitat és contribuir a promocionar, fomentar, divulgar, prestigiar, defensar i ampliar les actuacions i el patrimoni del Museu Marítim de Barcelona. També dona suport a la conservació del conjunt d'edificacions d'interès cultural que formen les Drassanes Reials de Barcelona. La Fundació obre el Museu a la participació i colllaboració de les entitats, molt especialment la de les empreses que puguin dinamitzar l'activitat marítima i portuària. Vol establir-se així com una plataforma de lligams i complicitats entre el món econòmic i el món de la cultura marítima. 
ció, però que alhora havien d'anar confluint per tal d'anar configurant el projecte comú. Els tres moments són: la cerca documental en els diferents arxius, la redacció d'una memòria individual corresponent al període assignat $i$, finalment, la redacció d'una memòria conjunta que doni coherència i homogeneïtat a la recerca.

L'altre repte era trobar les persones adients per dur a terme la recerca. Aquest projecte, pel seu abast, l'especificitat i la dedicació que requeria, no era assumible pel personal del Museu, per la qual cosa es va decidir que si es volia avançar i es volien obtenir resultats a mitjà termini, s'havia de recórrer a la contractació d'investigadors externs. Així, en el marc de les reunions de l'Observatori Permanent d'Història i Cultura Marítima de la Mediterrània es va fer la crida als representants de l'Àrea d'Història Moderna de la UB per tal de rebre suggeriments i poder seleccionar els investigadors que havien de dur a terme aquesta recerca. La resposta va ser ràpida i encertada, de manera que la recerca es va poder encarregar a dos investigadors solvents i coneixedors dels contextos històrics implicats, interessats per la temàtica i coneixedors dels fons arxivístics que calia indagar i estudiar.

Els investigadors que estan realitzant la recerca són: per a la primera part del segle Xvi, Jorge Aguilera López, i per a la segona part del segle XVII i principis del XVIII, el Dr. Alfredo Chamorro Esteban. Els dos investigadors no havien treballat junts directament però es coneixien personalment i van estar d'acord i disposats en tot moment a treballar en equip, fet que ha estat molt beneficiós per al desenvolupament del projecte. Cada investigador treballa de manera independent, amb reunions periòdiques amb els tècnics del Museu, i redacta un informe sobre la marxa de la investigació cada sis mesos. Aquests informes, juntament amb les reunions de treball, han servit per anar definint l'estratègia que s'ha de seguir en cada moment, valorant els resultats obtinguts, i per anar redefinint el guió del redactat final, per tal de donar coherència i homogeneïtat als resultats de la investigació de les dues parts cronològiques. Aguilera i Chamorro participen en aquest dossier amb un avanç de les investigacions respectives, on trobareu el detall de la documentació localitzada i al seu abast. 


\subsection{Metodologia de treball: preguntes i necessitats}

Els treballs es van iniciar amb la cerca de la documentació del període en qüestió en els diferents arxius. L'escassa atenció que fins a aquest moment s'havia prestat a l'estudi de les Drassanes en l'època moderna, ens proporcionava també un relatiu desconeixement dels fons disponibles sobre les Drassanes Reials de Barcelona en aquesta cronologia, el seu abast i quina seria la seva riquesa d'informació.

Una gran part de la documentació està localitzada en arxius de fora de Catalunya (a l'Archivo de Simancas, per exemple) i això ha fet que els investigadors hagin de viatjar. Per minimitzar els costos dels desplaçaments i fer-los més productius, es va decidir demanar còpies massives de la documentació i aprofitar el temps a localitzar el màxim de documentació relativa a les Drassanes de Barcelona, amb la idea d'analitzar-la i estudiar-la posteriorment amb calma des de Barcelona. Es va creure que el més adient era que el Museu assumís els costos de les reproduccions i, una vegada finalitzada la recerca, tota aquesta documentació reproduïda quedés al Museu perquè pogués ser utilitzada en recerques posteriors.

És el moment de recordar que no existeix un arxiu de les Drassanes Reials com a institució. Potser no ha existit mai, pel fet que han estat diverses les institucions que hi han tingut a veure. Davant de la dispersió de la documentació $i$ la inexistència d'un fons unitari que faci referència a la seva història, tant com a institució com a factoria naval, el projecte de recerca Drassanes Reials té com a objectiu la reconstrucció «ideal» d'aquest arxiu, el punt de partida de la qual és la reconstrucció teòrica d'un quadre de classificació de l'arxiu d'un arsenal de galeres. La voluntat és en el futur anar completant aquest fons amb la nova documentació localitzada, tot i que la dinàmica mateixa de la investigació va fer impossible dissenyar un pla de digitalització prèvia, com ja hem dit a l'inici de l'estudi, perquè no es tenia massa clar quin era el panorama que es trobaria en aquest terreny. Així doncs, la tria de la documentació que s'ha de digitalitzar s'ha fet sobre la marxa i en funció de les necessitats de la recerca en curs, mirant de tenir perspectiva de les necessitats 
futures, però sense una planificació prèvia. En tot cas, aquesta inversió en digitalització de la documentació a la llarga facilitarà i incentivarà que es continuïn realitzant més estudis en el futur.

\subsection{Síntesi de la recerca feta i estat de la qüestió}

En el moment de redactar aquest article, el projecte de recerca encara no ha acabat. La fase de recollida de dades es pot donar per acabada, però està en procés la part segurament més difícil: la confecció d'un text de síntesi de la feina feta. Cada investigador ha de fer una síntesi de la seva part i conjuntament amb els tècnics del Museu han de confeccionar un text que reculli els resultats bàsics de la recerca. L'elaboració i el redactat d'aquesta publicació no són una tasca fácil, ja que cadascun dels períodes estudiats pels dos investigadors té les seves especificitats i aspectes que en funció de la informació trobada tenen més o menys pes en el conjunt de l'estudi. El resultat ha de ser un llibre que doni coherència a la recerca feta, unint rigor i capacitat comunicativa per a un públic no acadèmic. Un llibre que no esgotarà el tema, sinó que escriurà el guió de les futures recerques.

El compromís de la publicació respon a la necessitat de donar visibilitat als resultats de la recerca per a un sector de públic tan ampli com sigui possible, ja que una de les missions dels museus és fer difusió del coneixement. Per altra banda, donar compte dels resultats de la recerca d'una forma relativament ràpida pot facilitar l'afluència de recursos.

El text final haurà de donar resposta a algunes de les qüestions plantejades pel que fa al funcionament de les Drassanes, la cronologia de les fases constructives de l'edifici (si és possible, tancar la dialèctica entre els resultats de la recerca arqueològica i les fonts documentals), l'impacte econòmic sobre la ciutat i sobre el país, el paper de les diferents administracions, el rol de les Drassanes Reials de Barcelona dins del sistema defensiu de la Monarquia Hispànica, etc. I, per sobre de tot, aportar dades que permetin una relectura de la història de Barcelona i de Catalunya.

A l'espera de la publicació del resultat de la recerca realitzada per Jorge Aguilera i Alfredo Chamorro, hi ha la intenció de trobar finança- 
ment per continuar la recerca i aprofundir en cadascun del fronts oberts en aquests dos anys. La digitalització de milers de documents obre la porta a un gran aprofundiment dels nostres coneixements sobre les Drassanes Reials dels segles XVI i XVII.

Podem avançar també que caldrà completar l'anàlisi del segle XVIII, especialment del període final de l'arsenal de galeres, fins al I745. 